\title{
Vitamin E Attenuates the Effects of FMLP on Rabbit Circulating Granulocytes
}

\author{
J. E. LAFUZE, (21) S. J. WEISMAN, L. A. ALPERT, AND R. L. BAEHNER \\ Division of Pediatric Hematology/Oncology Department of Pediatrics, James Whitcomb Riley Hospital for \\ Children, Indiana University School of Medicine, Indianapolis, Indiana, USA
}

\begin{abstract}
Summary
Exposure of circulating rabbit granulocytes to the chemoattractant $N$-formyl-methionyl-leucyl-phenylalanine (FMLP) in vivo results in transient granulocytopenia, hypotension, and cardiorespiratory distress. The effectiveness of vitamin $E$ in attenuating these responses was tested. Vitamin $E$ accelerated the rate of return of granulocytes to the peripheral circulation after FMLP-induced granulocytopenia and mitigated the hypotension. The reversible adherence of FMLP-stimulated granulocytes to endothelium offers a plausible mechanism to explain the transient granulocytopenia. From in vitro studies it was found that FMLPactivated granulocytes from animals treated with vitamin E showed decreased adherence to cultivated aortic endothelial monolayers when compared with FMLP-activated granulocytes from control animals.
\end{abstract}

\section{Abbreviations}

AGC, absolute granulocyte count

FMLP, $N$-formyl-methionyl-leucyl-phenylalanine

FMLP, a chemotactic peptide, mimics the action of certain bacterial filtrates on blood granulocytes in vivo and in vitro (11, $19,20)$. It is this activation of the granulocyte which brings about elevated oxidative activity and the release of superoxide ion, hydroxyl radical, and hydrogen peroxide $(9,12,18)$. These agents are essential in the role of granulocytic action against invading microorganisms. In addition, the activated granulocytes degranulate, increase their membrane adhesiveness, aggregate with each other, and adhere to artificial and other cellular surfaces $(7,10$, 18). The intravenous infusion of FMLP into rabbits causes a dramatic but transient granulocytopenia, significant hypotension, and cardiorespiratory alterations (11). The transient granulocytopenia might be due to the reversible adherence of activated granulocytes to vascular endothelium and the intravascular aggregation of these cells $(8,10,13)$. It is possible that during their absence from the peripheral circulation, the sequestered granulocytes block the microvasculature of the lung and other organs and release oxidative by-products which damage endothelium. In the pulmonary vasculature, this sequence of events could contribute to respiratory distress; therefore, the very mechanisms which serve to protect the host against bacterial invasion may lead to host damage if an inflammatory response is excessive or misdirected. It seems desirable to seek therapies to mitigate the damaging effects of excessive granulocyte activation.

Granulocytes from humans receiving $1600 \mathrm{U} / \mathrm{d}$ of vitamin $\mathrm{E}$ show reduced oxidative activity in vitro (1). We therefore tested the effects of vitamin E pretreatment of rabbits on their in vivo response to intravenous infusion of FMLP by comparing these responses to those of control rabbits which did not receive vitamin $\mathrm{E}$.

\section{MATERIALS AND METHODS}

Animals and anesthesia. Animals used in all aspects of this study were adult, male, New Zealand white rabbits weighing 2.0$3.0 \mathrm{~kg}$. Rabbits were anesthetized by an intramuscular injection of a mixture of ketamine $(100 \mathrm{mg})$, acetyl-promazine $(22 \mathrm{mg})$ and atropine sulfate $(5 \mathrm{mg})$, at a dose of $44 \mathrm{mg} / \mathrm{kg}$ of ketamine.

Vitamin E treatment of rabbits. Rabbits were injected intramuscularly with $2 \mathrm{ml}$ of vitamin $\mathrm{E}$ ( $100 \mathrm{mg}$ dl-alpha-tocopherol in vehicle) or the placebo control for $4 \mathrm{~d}$ before surgery. The vitamin $E$ and placebo were gifts from Dr. H.N. Bhagavan of Hoffman-La Roche, Nutley, New Jersey. The vehicle consisted of $0.2 \mathrm{ml}$ ethyl alcohol U.S.P. 200 proof, $0.2 \mathrm{ml}$ propylene glycerol U.S.P., $0.2 \mathrm{ml}$ emulphor EL-620, $0.02 \mathrm{ml}$ benzyl alcohol N.F., $0.6 \mathrm{mg}$ sodium acetate trihydrate, $5.0 \mathrm{mg}$ glacial acetic acid, $18.0 \mathrm{mg}$ sodium chloride, $0.2 \mathrm{mg}$ disodium edetate, $2 \mathrm{ml}$ sodium hydroxide $10 \%$ q.s. to $\mathrm{pH} 4$, and water for injection. The serum levels of tocopherols in test and control animals were determined after $4 \mathrm{~d}$ of treatment by a modification of the micromethod assay of total tocopherols in blood serum by Quaife et al. (16).

Monitoring of rabbits during FMLP infusion. Polyethylene tubing was used to cannulate the right femoral artery and vein of anesthetized rabbits. The arterial cannula was flushed with sterile, non-pyrogenic $0.95 \%$ saline (Abbot Laboratories, North Chicago, IL) and connected to a pressure transducer (HewlittPackard Inc., Waltham, MA). Both the arterial and venous cannulae were kept patent by pump perfusion of sterile saline at a flow rate of $4.1 \mathrm{ml} / \mathrm{h}$ (Sage Instruments Division of Research Syringe Pump Model 341 A).

FMLP (Sigma Chemical Co., St. Louis, MO) was dissolved in $0.02 \mathrm{M}$ sodium bicarbonate to a concentration of $1 \mathrm{mg} / \mathrm{ml}$ and diluted with phosphate buffered saline to a final concentration of $0.5 \mu \mathrm{g} / 2.5 \mathrm{~kg}$ rabbit. Samples of venous blood were collected in EDTA tubes (Becton-Dickinson Co., Rutherford, NJ) at time $0,2.5,5,10$, and $15 \mathrm{~min}$ after intravenous infusion of FMLP. The samples were immediately placed on ice for subsequent determination of AGC. Arterial blood samples were simultaneously collected in heparinized syringes for $\mathrm{PO}_{2}, \mathrm{PCO}_{2}$, and $\mathrm{pH}$ using the $\mathrm{pH}$ blood gas analyzer (Model 813, Instrument Laboratories, Lexington, MA).

Hewlitt-Packard Blood Pressure Monitor Model 78205B and Impedence Apnea Monitor Model $78212 \mathrm{C}$ were used to measure heart rate and respiratory rate, respectively. Recording was made on an Apple II microcomputer (Apple Computer, Inc. Cupertino, $\mathrm{CA}$ ) interfaced through a twelve bit analog to an Interactive Structures Model AI-13 (Bala Cynwyd, PA) digital converter. 
Kinetic study of activated granulocytes in vivo. Rabbit granulocytes were labeled with $\left[{ }^{3} \mathrm{H}\right]$ thymidine by a modification of the method of Price and Dale (15). Briefly, a rabbit weighing approximately $2.5 \mathrm{~kg}$ was injected intravenously with $2 \mathrm{mCi}$ of $\left[{ }^{3} \mathrm{H}\right]$ thymidine $(40-60 \mathrm{Ci} / \mathrm{m}$; New England Nuclear, Boston, MA). Seventy-two hours after the isotope injection, $75 \mathrm{ml}$ of blood was removed via the femoral artery and collected in $15 \mathrm{ml}$ of acid-citrate-dextrose. Ten milliliters of the collected blood was exchanged via the femoral vein for $10 \mathrm{ml}$ of blood from each of three recipient rabbits. Two of the recipient animals received intravenous infusion of $0.5 \mu \mathrm{g}$ dose of FMLP after a 2-min equilibration period. Six milliliters of blood was taken from the control (one non-challenged animal) and two test animals at time $0,2.5,10,15,30$, and $60 \mathrm{~min}$. Each sample was layered over $3 \mathrm{ml}$ of a mixture of 10 parts of $33.9 \%$ Hypaque and 24 parts of $9 \%$ Ficoll in $13 \times 15 \mathrm{~mm}$ plastic tubes and then centrifuged at $400 \mathrm{~g}$ for $35 \mathrm{~min}$ at $22^{\circ} \mathrm{C}$. Thereafter, the supernatant, buffy coat containing the mononuclear cells and the top $2 \mathrm{~mm}$ of the erythrocyte pellet were discarded. Six milliliters of $3 \%$ dextran in $0.9 \%$ saline was added to the pellet and the contents were thoroughly mixed. The tubes were placed at a $45^{\circ}$ angle and the erythrocytes were allowed to sediment for $90 \mathrm{~min}$ or until there was a clear demarcation between the interface layer containing the granulocytes and the erythrocyte pellet. The pellet was discarded and the granulocyte layer was centrifuged for 10 min at $22^{\circ} \mathrm{C}$. The supernatant was discarded. $\mathrm{NH}_{4} \mathrm{Cl}, 0.8 \%$, was used to lyse erythrocytes remaining in the pellet containing the granulocytes. Each centrifugation was for $10 \mathrm{~min}$ at $400 \mathrm{~g}$ at $22^{\circ} \mathrm{C}$. One milliliter of 8:2 Soluene- 350 (Packard Instrument Co., Inc., Downers Grove, IL.) was added to the granulocyte pellet and incubated for at least $4 \mathrm{~h}$ at $37^{\circ} \mathrm{C}$ to solubilize the cells. Thereafter, the samples were suspended in $10 \mathrm{ml}$ of Scint-O (Packard Instrument Co., Inc.) and the samples were counted in a liquid scintilation counter (Packard Instrument Co., Inc.).

Preparation of rabbit granulocytes for in vitro adherence. Blood was collected from the femoral artery of anesthetized rabbits in a 1:7 volume of acid-citrate-dextrose to blood. A modification of Henson's procedure was used to isolate granulocytes (6). Briefly, $45 \mathrm{ml}$ of blood were centrifuged in polypropylene tubes at $550 \mathrm{~g}$ for $20 \mathrm{~min}$ at $22^{\circ} \mathrm{C}$. The plasma, buffy coat, and top 2 $\mathrm{mm}$ of red cell pellet were discarded. The tube containing the erythrocytes and leukocytes (of which $75-95 \%$ were granulocytes) was filled with approximately $30 \mathrm{ml}$ of $2.5 \%$ gelatin (Difco Laboratories, Detroit, MI). The gelatin was dissolved in pyrogenfree saline and autoclaved for $1 \mathrm{~min}$ on the same day it was to be used. It was allowed to cool to $37^{\circ} \mathrm{C}$.

The blood-gelatin mixture was drawn up into 60-cc syringes which were inverted and taped at the bottom of the barrel to the shelf of a $37^{\circ}$ incubator. The erythrocytes were allowed to sediment for $45 \mathrm{~min}$. The supernatant (containing the granulocytes) was expressed through an 18 gauge needle bent at a $45^{\circ}$ angle into $50-\mathrm{ml}$ polypropylene conical centrifuge tubes. The cells in this supernatant were centrifuged at $400 \mathrm{~g}$ for $10 \mathrm{~min}$ at $22^{\circ} \mathrm{C}$. The button was resuspended in $0.2 \%$ saline for $30 \mathrm{~s}$, after which an equal volume of $1.6 \%$ saline was added. The cells were sedimented at $200 \mathrm{~g}$ for $10 \mathrm{~min} 4^{\circ} \mathrm{C}$, washed once with Tyrode's albumin solution, resuspended in this mixture, and kept on ice until used.

Granulocyte adherence to cultured rabbit aortic endothelial monolayers. A modified method of Beesley et al. (2) was used to determine adherence. Rabbit aortic endothelial cells were grown to confluence in plates with 12 cluster wells (Costar, Data Packaging Corporation, Cambridge, MA). The cells were a gift from the established rabbit aortic endothelial cultures of Drs. Buonassisi and Colburn, Departments of Biology, Medicine and Chemistry, University of California at San Diego, La Jolla, CA $(3,5)$. On the day of experiment, the monolayers were washed three times with Earle's salt solution containing $10 \%$ fetal bovine serum. Each well was filled with $0.8 \mathrm{ml}$ of Ham's Nutrient
Mixture F-12 (Gibco Laboratories, Grand Island, NY), with 10\% fetal bovine serum, and incubated for $5 \mathrm{~min}$.

The isolated rabbit granulocytes were incubated separately in nutrient mixture $\mathrm{F}-12$ for $5 \mathrm{~min}$. At the time of testing, $0.1 \mathrm{ml}$ of the cells (final concentration $10^{6}$ granulocytes $/ \mathrm{ml}$ ) was added to each well and $0.1 \mathrm{ml}$ of FMLP (final concentration $1 \times 10^{-7}$ $\mathrm{M}$ in dimethyl sulfoxide $0.1 \%$ ) was added. The plate was rotated briefly for mixing and incubated for $10 \mathrm{~min}$ at $37^{\circ} \mathrm{C}$ with $5 \%$ $\mathrm{CO}_{2}$. The medium was washed across the surface of the well and decanted. The plates were allowed to air dry and stained with Diff-Quick Stain (American Scientific Products, McGaw Park, IL). Adherent granulocytes were counted in triplicate wells using a total of nine high power fields. Results are reported per high power $(\times 45)$ field $/ 10^{6}$ cells plated.

\section{RESULTS}

Vitamin E levels. Serum levels of vitamin $\mathrm{E}$ were more than 10 times greater in the animals receiving vitamin $\mathrm{E}$ as compared with controls $(2.34 \pm 0.15 \mathrm{mg} \%$ versus $0.19 \pm 0.04 \mathrm{mg} \%)$.

Influence of vitamin $E$ on the response to granulocyte activation In Vivo. As noted in Figure 1, after infusion of FMLP there was a dramatic decrease in the circulating AGC in both the control and vitamin E-treated rabbits. The AGC dropped to $10 \%$ of initial values within $2.5 \mathrm{~min}$ after FMLP infusion in both groups. Over the subsequent $15 \mathrm{~min}$, the AGC returned to approximately $20 \%$ of initial values in control rabbits. On the other hand, in contrast to the normal response, the rate of return was significantly increased in the rabbits receiving vitamin $\mathrm{E}$.

As noted in Figure 2, the AGC in vitamin E-treated rabbits had returned to approximately $75 \%$ of initial values at $15 \mathrm{~min}$. Also, the mean arterial blood pressure decreased in both control and vitamin E-treated rabbits (Fig. 2). But there was significantly greater return toward initial values in the vitamin E-treated animals. Likewise, the heart rate was more stable throughout the period of observation and the respiratory distress was less apparent in vitamin E-treated rabbits at 15 min (Figs. 3 and 4).

Kinetics of circulating granulocytes. As noted in Figure 5 , the labeled granulocytes decreased almost $50 \%$ in the first $2.5 \mathrm{~min}$ and remained stable at the $45 \%$ level through the 30 - and $60-$ min intervals in the control animal which did not receive FMLP. In contrast, circulating labeled granulocytes in the rabbits which received FMLP decreased dramatically in the first $2.5 \mathrm{~min}$. At $10 \mathrm{~min}$, there was a modest increase in radioactivity and the rate

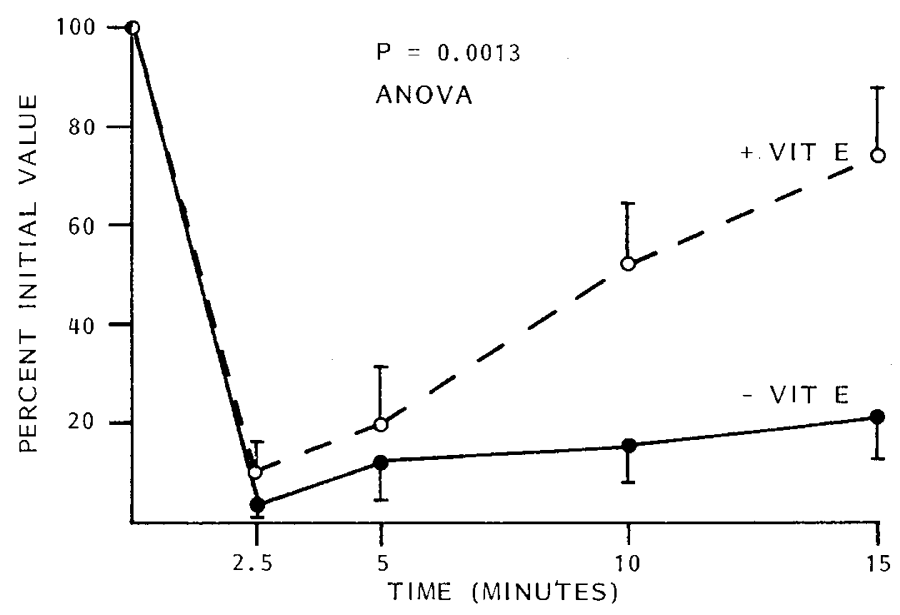

Fig. 1. Absolute granulocyte count during infusion of $N$-formyl-methionyl-leucyl-phenylalanine (FMLP) in rabbits. Results are expressed as percentage of initial value and time is expressed in minutes after FMLP infusion. Values are expressed as mean $\pm \mathrm{SD}$. The solid line represents control rabbits and the dotted line represents rabbits receiving vitamin E. $N$ equal three animals for each group. 


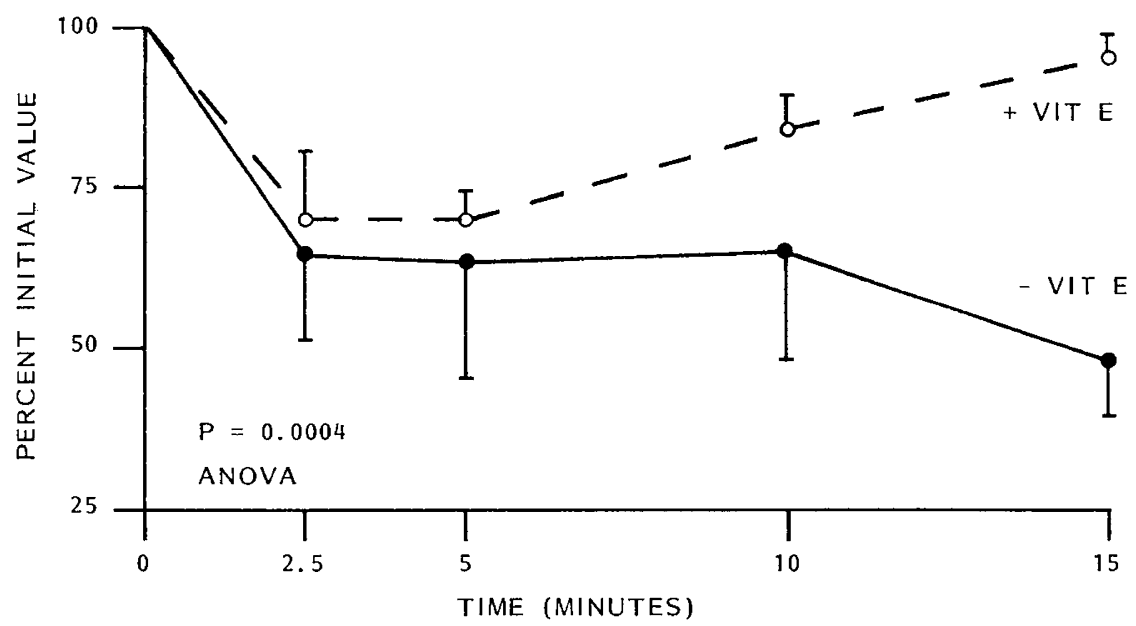

Fig. 2. Mean arterial blood pressure during $N$-formyl-methionyl-leucyl-phenylalanine (FMLP) infusion of rabbits. Values are expressed as percentage of initial value and time represents minutes after infusion of FMLP. Values are expressed as mean \pm SD. The solid line represents control rabbits and the dotted line represents rabbits receiving vitamin $\mathrm{E}$. $N$ equal three animals for each group.

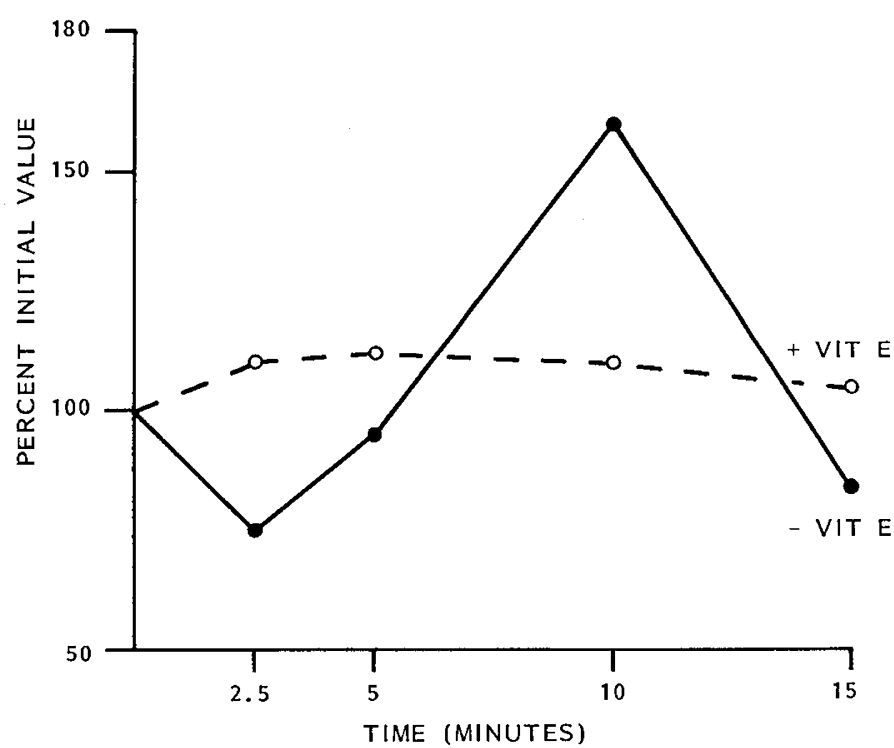

Fig. 3. Effects of $N$-formyl-methionyl-leucyl-phenylalanine (FMLP) infusion on rabbit heart rate. Values are expressed as percentage of initial value and time represents minutes after infusion of FMLP. The solid line represents control rabbits and the dotted line represents rabbits receiving vitamin $\mathrm{E}$. $N$ equal three animals for each group.

of increase was approximately linear over the final $45-\mathrm{min}$ period. The percentage of the radioactivity at $60 \mathrm{~min}$ surpassed the 60 min value of the control.

Endothelial monolayer studies. Resting granulocytes from vitamin E-treated rabbits and from rabbits not receiving vitamin $E$ adhered moderately to the endothelial monolayers (Fig. 6). There were $67.3 \pm 7.0$ cell/high power field in the placebotreated animals and $66.5 \pm 8.5$ cell/high power field in rabbits treated with vitamin E. Exposure of the granulocytes from rabbits not receiving vitamin $E$ to $10^{-7} \mathrm{M}$ FMLP increased their adherence to the endothelial monolayers. There were $85.3 \pm 6.3$ cell/ high power field for those granulocytes from rabbits not receiving vitamin $\mathrm{E}$, compared with $69.3 \pm 5$ cell/high power field for those granulocytes from rabbits receiving vitamin $\mathrm{E}(P=0.03)$. On the other hand, no significant increase in adherence was observed when granulocytes from vitamin E-treated rabbits were stimulated with FMLP compared with non-stimulated granulocytes. FMLP-stimulated granulocytes from vitamin E-treated rabbits were, thus, significantly impaired in their ability to adhere to endothelial monolayers compared with FMLP-stimulated granulocytes from non-treated rabbits $(P=0.03)$.

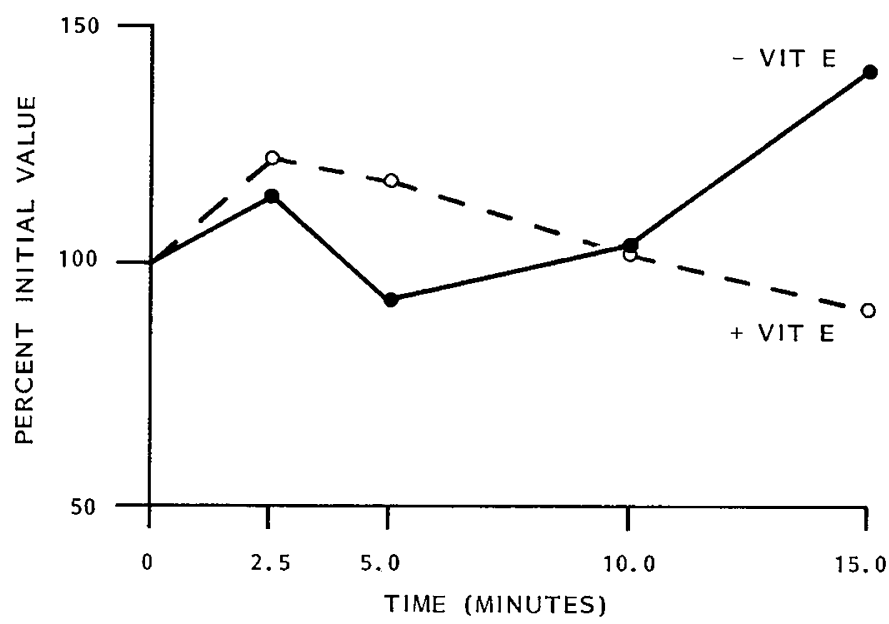

Fig. 4. Effects of $N$-formyl-methionyl-leucyl-phenylalanine (FMLP) infusion on rabbit respiratory rate. Values are expressed as percentage of initial value and time represents minutes after infusion of FMLP. The solid line represents control rabbits and the dotted line represents rabbits receiving vitamin $\mathrm{E}$. $N$ equal three animals for each group.

\section{DISCUSSION}

The in vivo responses to granulocyte activation by intravenous infusion of FMLP include granulocytopenia, a subsequent decrease in blood pressure, and fluctuation in the cardiorespiratory status of the animal. The fact that granulocytes return to the peripheral circulation poses the question of whether the granulocytes in this return are newly released from the bone marrow or are, indeed, the same cells which were originally part of the circulating peripheral pool of granulocytes. The results of this study, obtained by employing non-eluting $\left[{ }^{3} \mathrm{H}\right]$ thymidine tagged granulocytes from a donor rabbit, suggest that the returning cells were from the original circulating pool, because they contained radioactivity in amounts which equaled or even surpassed the original values. In addition, the kinetic course of radioactivity paralleled the return of AGC toward baseline values after infusion of FMLP.

The physiologic basis for the granulocytopenia, hypotension, and cardiorespiratory distress is thought to involve the interactions between granulocytes and the microvasculature. FMLP stimulates the granulocytes metabolically to release reduced oxygen by-products. In addition, there are membrane changes which lead to their enhanced adherence to endothelial cells and increase aggregation to other circulating granulocytes.

Vitamin $E$ had a significant effect in enhancing the rate of 


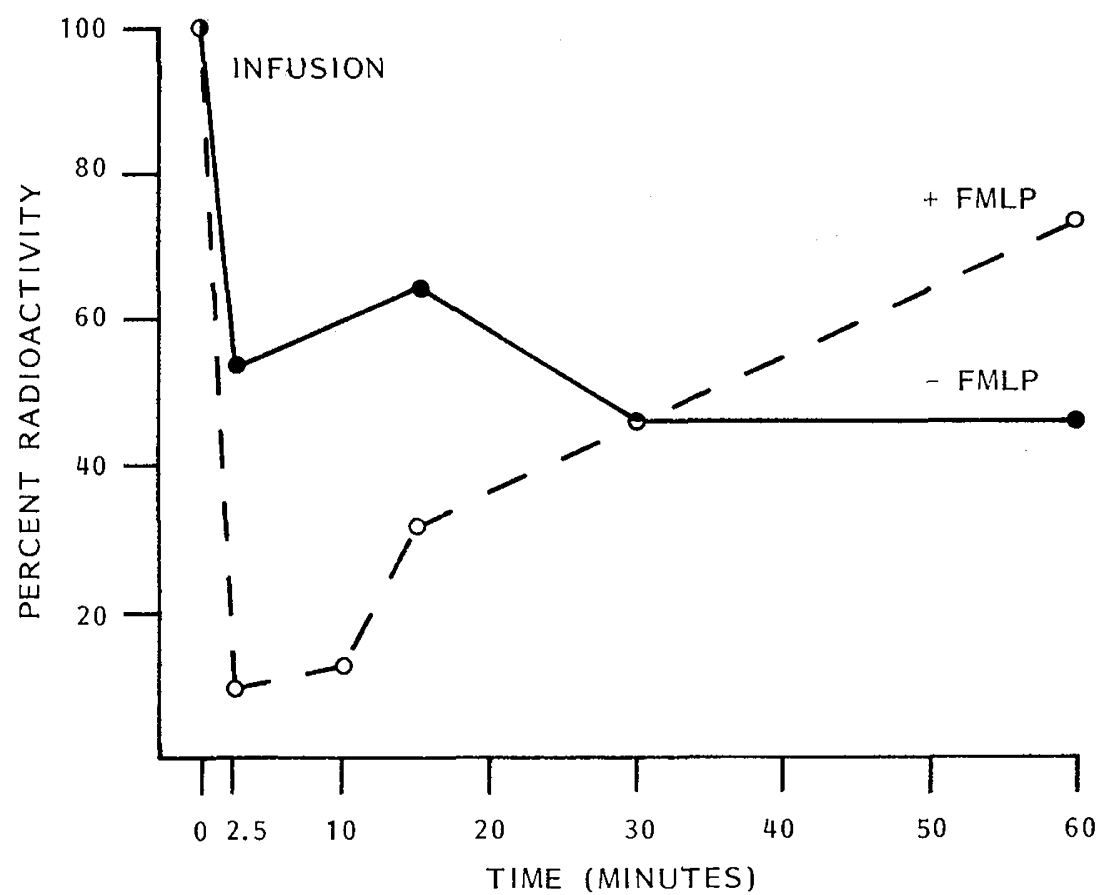

Fig. 5. Effects of $N$-formyl-methionyl-leucyl-phenylalanine (FMLP) infusion on $\left[{ }^{3} \mathrm{H}\right]$ thymidine rabbit granulocytes. Results are expressed as percentage of initial radioactivity and time after infusion of FMLP is expressed in minutes. The solid line represents control values of an animal which did not receive FMLP. The dotted line represents the mean values of two animals which received FMLP.

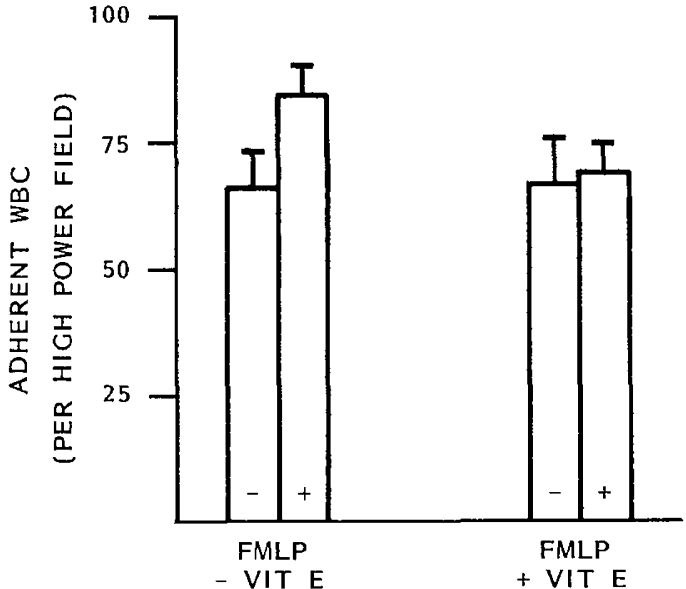

Fig. 6. The effects of FMLP on granulocyte adherence to cultured rabbit aortic endothelial monolayer in vitro. Values are expressed as adherent white blood cell/high power field. Values represent mean \pm SD. Cells were used from three animals in each group.

recovery of the AGC. It also enhanced the recovery of the lowered mean blood pressure following FMLP infusion. Furthermore, the vitamin E-treated rabbits showed less cardiorespiratory distress. The exact in vivo mechanism by which vitamin $\mathrm{E}$ mitigates these effects of granulocyte activation is not known at present, but may involve its anti-oxidant and biophysical properties and its effects on the cell membrane. Previous studies indicated that granulocytes from human volunteers receiving $1600 \mathrm{U}$ of vitamin $\mathrm{E}$ daily have a mild decrease in bactericidal potency and marked impairment of $\mathrm{H}_{2} \mathrm{O}_{2}$ release (1). Quintanilha et al. (17) noted that vitamin $\mathrm{E}$ deficiency causes alterations of rat mitochondrial membrane surface potential. They observed small changes in membrane surface charge density and increased sensitivity to oxidant-induced damage with greater negative surface potential in the membranes from rats with vitamin $E$ deficiency. The phenomenon is related to lipid peroxidation and loss of functional membrane integrity. Although antioxidants slow each process, it is not known whether functional losses facilitate lipid peroxidation or whether lipid peroxidation brings about changes in structural stability.

Butterick et al. (4) have shown that intact granules from vitamin E-treated human subjects showed unchanged oxygen consumption but significantly reduced rates of hydrogen peroxide dependent glucose- $1-{ }^{14} \mathrm{C}$ oxidation to ${ }^{14} \mathrm{CO}_{2}$. The authors propose the possibility that vitamin $\mathrm{E}$ exerts a selective inhibition by disruption of electron flow from NADPH to $\mathrm{O}_{2}$ in the electron transport chain, resulting in less $\mathrm{H}_{2} \mathrm{O}_{2}$ release for those granulocytes.

Our in vitro studies confirm that activated granulocytes have greater adherence to rabbit aortic endothelial monolayers than do resting cells. Furthermore, vitamin $\mathrm{E}$ attenuates the degree to which rabbit granulocytes adhere to endothelial surfaces after FMLP activation in vitro. The exact mechanism for this attenuation is not known, but it is possible that the vitamin $\mathrm{E}$ acts metabolically to decrease $\mathrm{H}_{2} \mathrm{O}_{2}$ release or may bring about membrane structural and functional changes. Vitamin $\mathrm{E}$ may provide protection to endothelial surfaces during the inflammatory response by modifying the function of activated granulocytes.

\section{REFERENCES AND NOTES}

1. Baehner, R. L., Boxer, L. A., Ingraham, L. M., Butterick, C. J., and Haak, R. The influence of vitamin $E$ on human polymorphonuclear cell metabolism and function. In: B. Lubin and L. J. Machlin: Vitamin E: Biochemical, Hematological, and Clinical Aspects. Ann. N. Y. Acad. Sci., 393: 237 (1982)

2. Beesley, J. E., Pearson, J. D., Hutchings, A., Carleton, J. S., and Gordon, J. L.: Granulocyte migration through endothelium in culture. J. Cell. Sci., 38: 237 (1979).

3. Buonassisi, V. and Venter, J. C.: Hormone and neurotransmitter receptors in an established vascular endothelial cell line. Proc. Natl. Acad. Sci. U.S.A. Cell. Biol., 73: 1612 (1976).

4. Butterick, C. J., Baehner, R. L., Boxer, L. A., and Jersild, R. A., Jr.: Vitamin E: a selective inhibitor of the NADPH oxido-reductase enzyme system in human granulocytes. Am. J. Pathol., 112 (3): 287 (1983).

5. Colburn, P. and Buonassisi, V.: Anti-clotting activity of endothelial cell cultures and heparin sulfate proteoglycans. Biochem. Biophys. Res. Commun., 104. 220 (1982).

6. Henson, P. M.: The immunologic release of constituents from neutrophil leukocytes. I. The role of antibody and complement on nonphagocytosable surfaces or phagocytosable particles. Immunology, 107: 1535 (1971).

7. Hoover, R. L., Folger, R., Haering, W. A., Ware, B. R., and Karnovsky, M. J. Adhesion of leukocytes to endothelium: roles of divalent cations, surface charge, chemotactic agents, and substrate. J. Cell. Sci., 45: 73 (1980). 
8. Jacob, H. S.: Complement-induced vascular leukostasis: its role in tissue injury. Arch. Pathol. Lab. Med., 104:617 (1980).

9. Johnston, R. B., Jr. and Lehmeyer, J. E.: Elaboration of toxic oxygen byproducts by neutrophils in a model of immune complex disease. J. Clin. Invest., 57: 836 (1976).

10. Lafuze, J. E., Weisman, S. J., Ingraham, L. M., and Baehner, R. L.: Vitamin $\mathrm{E}$ in vivo and in vitro effects on granulocytes. Pediatr. Res. (abstract), 17. 236A (1982)

11. Lash, J. A., Coates, T. D., Lafuze, J. E., Baehner, R. L., and Boxer, L. A.: Plasma lactoferrin reflects granulocyte activation in vivo. Blood, 61: 885 (1983).

12. McPhail, L. C., Henson, P. M., and Johnston, R. B., Jr.: Respiratory burst enzyme in human neutrophils: evidence for multiple mechanisms of activation. J. Clin. Invest., 67: 710 (1981).

13. O'Flaherty, J. T., Showell, H. J., and Ward, P. A.: Neutropenia induced by systemic infusion of chemotactic factors. J. Immunol., 118: 1586 (1977).

14. O'Flaherty, J. T. and Ward, P. A.: Chemotactic factors and the neutrophil. Semin. Hematol., 16: 163 (1979).

15. Price, T. H. and Dale, D. C.: Neutrophil preservation: the effect of short-term storage on in vivo kinetics. J. Clin. Invest., 59: 475 (1977).

16. Quaife, M. C., Scrimshaw, N. S., and Lowry, O. H.: A micromethod for assay of total tocopherols in blood serum. J. Biol. Chem., 180: 1229 (1949).

17. Quintanilha, A. T., Packer, L., Davies, J. M. S., Racanelli, T. L., and Davies, K. J. A.: Membrane effects of Vitamin E deficiency: Bioenergetic and surface charge density studies of skeletal muscle and liver mitochondria. In: B. Lubin and L. J. Machlin: Vitamin E: Biochemical, Hematological and Clinical aspects. Ann. N. Y. Acad. Sci., 393: 32 (1982).

18. Sacks, T., Moldow, C. F., Craddock, P. R., Bowers, T. K., and Jacob, H. S.: Oxygen radicals mediate endothelial cell damage by complement-stimulated granulocytes: an in vitro model of immune vascular damage. J. Clin. Invest., 61: 1161 (1978).

19. Schiffmann, E Showell, H. V Corcoran, B. A., Ward, P. A., Smith, E, and Becker, E. L.: The isolation and partial characterization of neutrophil chemotactic factors from Escherichia coli. J. Immunol., 114: 1831 (1975).

20. Williams, L. T., Snyderman, R., Pike, M. C., and Lefkowitz, R. J.: Specific receptor sites for chemotactic peptides on human polymorphonuclear leukocytes. Proc. Natl. Acad. Sci. U.S.A., 74: 1204 (1977).

21. Requests for reprints should be addressed to: Dr. J. E. LaFuze, Div. of Pediatric Hematology/Oncology, Dept. of Pediatrics, James Whitcomb Riley Hospital for Children, IN University School of Medicine, Indianapolis, IN 46223.

22. The authors thank Bonnie McGarr for her excellent technical assistance, to Drs. Pao-Lo Yu and Thomas D. Coates for their assistance with the statistical analysis and to Dawn Castle for her help in preparing the manuscript.

23. This research was supported by National Institutes of Health grant numbers AI-10892 and T32 AM 7193 and a grant from the Riley Memorial Association. We also acknowledge the support of Riley Cancer Research for Children, Inc.

24. Received for publication May 6, 1983.

24. Accepted for publication August 17, 1983.

\title{
A Purified Serum Glycopeptide from Controls and Cystic Fibrosis Patients. III. The Association of the Ciliary Dyskinetic Activity with the Oligosaccharide Component
}

\author{
MIRIAM G. BLITZER AND EMMANUEL SHAPIRA ${ }^{(19)}$ \\ The Hayward Genetics Center, Departments of Pathology, Pediatrics and Biochemistry, Tulane University \\ School of Medicine, New Orleans, Louisiana USA
}

\section{Summary}

We have previously described the purification and partial characterization of a serum glycopeptide with mucociliary activity from cystic fibrosis patients and a normal counterpart from sera of controls $(3,4)$. After removal of its oligosaccharide component by $\beta$-elimination, the peptide portion of the glycopeptide from cystic fibrosis patients did not reveal any mucociliary activity on rabbit tracheal explants. This mucociliary activity was shown to be inhibited by mannose, glucose, and $N$-acetyl-galactosamine as well as by the glycopeptide purified from controls. It was not affected by xylose, fucose, galactose, or $\mathrm{N}$-acetyl-glucosamine.

\section{Abbreviations}

CF, cystic fibrosis

PBS, phosphate buffered saline

The presence of a CF-specific factor affecting the rhythmic beat of cilia from rabbit tracheal explants was first described in 1967 by Spock et al. (16). These authors documented this biologic activity (ciliary dyskinesia) in CF sera and the euglobulin fraction from both patients and CF obligate heterozygotes, but not from most normal controls. Subsequently, this factor or other factors was observed to disrupt the ciliary rhythm in other ciliated organisms $(2,6,10)$ and found to be present in various biologic fluids from $\mathrm{CF}$ patients $(1,7,11,12)$. The ciliary dyskinetic factor from sera of CF patients has been partially purified and characterized by various groups $(5,8,9,17)$.

Recently (3) we purified a serum glycopeptide from CF patients that caused marked mucociliary dyskinetic activity on rabbit tracheal explants. Using the same methodology, a "normal counterpart" was purified from sera of controls that did not show any apparent biologic activity on rabbit tracheal explants, even in a 50 -fold higher concentration. Neither was found to contain sialic acid or aromatic amino acids. More recently, we compared (4) some of the immunologic properties of these glycopeptides using monoclonal antibody technology and found that the glycopeptide purified from controls acts as a better immunogen than the glycopeptide from CF patients. Antibodies directed toward the oligosaccharide component of the glycopeptide were found to crossreact with various glycoprotein preparations, whereas those directed toward the peptide component were specific to the glycopeptides. When the antibodies specific to the glycopeptides were used to compare serum fractions from controls and $\mathrm{CF}$ patients, indistinguishable immunologic reactivity (antigenicity) was demonstrated. 